\title{
LA OBRA DE FRANCISCO ZAMORA Y SU LECTOR IMPLÍCITO
}

\author{
POR \\ JUAN De URDA \\ SUNY-Fredonia
}

El guineano Francisco Zamora Loboch ha cultivado el verso, la ficción y el ensayo, y en todos los campos su creación es digna de interés. Pero en la escritura de Zamora diferentes géneros no presentan sólo diferentes recursos técnicos, sino también diferentes aproximaciones temáticas e incluso diferentes voces. La poesía se concentra en su pasado guineano y en el recuerdo de su cultura, de su infancia y juventud. La voz poética parece saturarse de melancolía y hay una continua mirada atrás que parece ser una búsqueda. En prosa adopta una actitud más provocadora y beligerante, claramente decidido a remover conciencias. La obra de Francisco Zamora encaja en las descripciones que Franz Fanon y Homi Bhabha elaboran sobre cómo escribe y crea un autor producto de la situación colonial y poscolonial. Teniendo siempre en cuenta esa diferencia temática y la situación en la que Zamora escribe y publica, en un país que no es el suyo, voy a analizar el papel del lector implícito en sus obras, siguiendo fundamentalmente las ideas de los críticos Wayne Booth y Walker Gibson.

Desde una perspectiva retórica, Wayne Booth escribe sobre el lector implícito de un texto, es decir, el lector que el propio texto crea. Booth no se refiere a la persona real y concreta, sino al lector que, dejando momentáneamente al lado sus propias creencias, se subordina al texto. Sólo así puede disfrutarlo completamente (138). En ese concepto Booth sigue las ideas de Walker Gibson, quien establece la figura del "lector fingido" ("mock reader"). Para Gibson, el lector fingido es la máscara que la persona individual usa cuando se enfrenta al lenguaje de un texto (266). Gibson aporta valiosos ejemplos de lo que él considera ese lector fingido y cómo funciona ese juego, pero aclara que algunas veces esa comunión con el texto simplemente no es posible. Escribe que esos son los libros que rechazamos como "malos libros", aquellos para los que no podemos convertirnos en el "lector fingido" porque se trata de una persona que no queremos ser, una máscara que no queremos llevar (268). Dadas las circunstancias editoriales, es posible saber algo del lector real de Zamora (por ejemplo, que va a ser probablemente español y no africano, al menos no por ahora); pero, ¿cómo es su lector implícito?

Francisco Zamora Loboch nació en Santa Isabel en 1948, veinte años antes de que Guinea Ecuatorial obtenga su independencia. En su juventud obtuvo una beca 
y se trasladó a España para cursar sus estudios universitarios (Antología 463). Y en España seguía residiendo cuando en 1968 concluye el proceso de independencia de Guinea. Como lo que se inició como un proceso democrático se trunca enseguida y la dictadura de Macías termina por imponerse, Zamora se queda a vivir en España, donde ha residido desde entonces. Juan Balboa Boneke afirmó de los escritores de su edad y circunstancias que eran la "generación perdida" (Ngom 1993 413-4) y Donato NDongo se refiere a esos años como "años del silencio" (413). Pero Zamora afirma que él nunca estuvo perdido en la entrevista incluida en Diálogos con Guinea (110-11) y ciertamente esos años no fueron de silencio literario para él. Pero es indudable que su vida y su obra han estado condicionadas por su situación de exiliado y la lejanía de su Guinea natal. Pero el exilio de Zamora es más complicado aun, porque su lugar de expatriación es la antigua potencia colonial de su país. Durante los años del franquismo la situación de Guinea fue declarada "materia reservada" y los exiliados no tuvieron la posibilidad de expresar su opinión ni sus protestas. Los gobiernos de la época democrática tampoco han favorecido la difusión de opiniones contrarias a la actual dictadura guineana.

Zamora niega pertenecer a ninguna generación "perdida", puesto que él se mantuvo literariamente creativo a pesar de las circunstancias adversas. De hecho, como Andrew Gurr afirma, en esas situaciones de exilio provocado por la situación colonial, los autores explotan sus circunstancias como fuerza creativa (xx). Sienten la necesidad de escribir sobre su situación y sus pérdidas. Necesitan recrear su país y su cultura ausentes. Durante sus primeros años de creación, Zamora publicó poemas y relatos, algunos de ellos con seudónimo. Su primera publicación más extensa fue un divertido y corrosivo ensayo sobre el racismo en España titulado Cómo ser negro y no morir en Aravaca, aparecido en 1994. Posteriormente publicó los libros de poemas Memoria de laberintos, de 1999, y Desde el Viyil y otras crónicas, de 2008. Recientemente ha aparecido una novela, Conspiración en el Green (el informe Avayak). Aunque no ha sido un autor especialmente prolífico, sí que es llamativo que ha tocado casi todos los géneros literarios. Por si fuera poco, es periodista, entrenador de fútbol, músico y compositor con varios discos grabados. Aunque su primera obra fue Cómo ser negro..., voy a comenzar con su obra poética.

La poesía de Zamora está contenida fundamentalmente en los dos libros Memoria de laberintos, del año 1999 y Desde el Viyil y otras crónicas, publicado en el año 2008. Anteriormente había publicado poesías sueltas que aparecieron en diversos medios, incluso en hojas volanderas. Esas poesías previas a Memoria de laberintos han sido incluidas en Desde el Viyil..., cobrando una sorprendente nueva vida entre poemas más recientes. En ambos volúmenes su poesía se desarrolla en versos libres de variada longitud, confiada en un ritmo firme. Zamora maneja bien el sonido de sus palabras, alternando expresiones coloquiales con un tono elevado. En la misma poesía caben "quien no sin cierta displicencia" y "me enseñó el bando que prohibía escupir en las aceras" (Memoria 56). Es la suya una poesía de referencia y espacios. De espacios porque los poemas son

Revista Iberoamericana, Vol. LXXX, Núms. 248-249, Julio-Diciembre 2014, 1067-1080 ISSN 0034-9631 (Impreso)

ISSN 2154-4794 (Electrónico) 
una geografía (Guinea, Madrid, su colegio, su dormitorio...) poblada por diferentes Zamoras (el Zamora niño, adolescente, africano, exiliado, hombre) y por personajes que de alguna manera han contribuido a la formación del ente que Francisco Zamora es (otros escritores, músicos, boxeadores, compañeros de colegio, dictadores, mujeres). En ese espacio conviven los Zamoras (el Zamora que mira desde el presente/futuro y la persona que fue en un instante de esas geografías) explicándose y componiéndose.

Esos espacios, sus figuras y el mundo que ellos representan y conforman son los temas de la poesía de Zamora. A pesar del tiempo transcurrido entre uno y otro poemario (y de la distancia temporal añadida entre algunos poemas de la segunda selección, que ya comentamos que incluye poemas tempranos de Zamora), se observa entre ellos unidad y coherencia, sobre todo temática. Justo Bolekia Boleká sostiene en el prólogo de Desde el Viyil... que la poesía de Zamora en ese volumen deja atrás su adolescencia colonial y escribe sobre experiencias “más adultas, más rotundas, más maduras” (7); pero no hace referencia a que algunos de los poemas del libro fueron publicados incluso antes de que Memoria de laberintos viera la luz. En algunos de los poemas en Desde el Viyil... la voz poética son los ojos de un niño, como en "Ambo Embo" (14) o "Vino de Palma" (15). En general, Zamora nos habla de los mismos temas y las mismas inquietudes: su pasado amoroso, los materiales culturales de su infancia y juventud, algunos personajes de aquellos años y retazos de la geografía, la sociedad y la historia de Guinea.

A simple vista parecen ingredientes dispersos, pero una segunda lectura de los poemarios revela que lo que Zamora está ponderando y considerando en esos versos es su propia identidad. Trazando una partición temática de los poemas que es quizá demasiado tajante (y, por lo tanto, simplista) podemos dividir los poemas en aquellos que indagan en la memoria colectiva guineana (antes y después de la independencia) y los que escrutan en su propia identidad de africano exiliado en su antigua metrópoli.

No en vano el título de su primer libro de poesía es Memoria de laberintos, que en una inversión léxica se convierte en laberinto de la memoria, en un lugar donde es fácil desorientarse pero que tiene un substancioso premio: la memoria, el pasado, la propia identidad. Y, en ambos poemarios, el orden temático de los poemas es laberíntico, no hay bloques definidos. O en esa exploración de la identidad da igual que el poema trate de la historia de Guinea a de la vida amorosa de Zamora, puesto que ambas realidades confluyen en lo que la voz poética es (o pudo ser, o quiso ser).

Acontecimientos de su vida privada (o las de personajes que la voz poética adopta como ficción) aparecen en poemas como "Bailaste con Mamen" (25) o "Madame" (22) en Memoria de laberintos. Otros ejemplos en Desde el Viyil... son "Versos para un día de lluvia" (28-9), "La piel del agua" (51) o "Nuestros eróticos y viciosos círculos" (53$63)$, otro de sus viejos poemas. Guinea y su historia son protagonistas en "Encuentro a Vida o Muerte en el Estadio Santa María" (Memoria 60-1) o "Reservada materia" (38). O en los poemas de Desde el Viyil... "Vamos al matar al tirano" (27), que es uno de los que ya había aparecido con antelación, o "África XXI” (31-2). En algunos poemas,

Revista Iberoamericana, Vol. LXXX, Núms. 248-249, Julio-Diciembre 2014, 1067-1080 ISSN 0034-9631 (Impreso)

ISSN 2154-4794 (Electrónico) 
la voz poética anuncia que está siendo portavoz de la memoria de personas y sucesos concretos. En "Dyoba, Nguema y Bokesa" (Memoria 32), después de rápidas referencias a estas tres vidas, sostiene que decidió "ejercer de escriba".

La mirada que Zamora dirige a su pasado parece indagadora o nostálgica. Explorar sus raíces, escrutar con la poesía al "otro" Zamora (niño, adolescente, joven), las figuras que los conformaron y la historia de su país y cultura es, según los principales teóricos de la literatura colonial y poscolonial, el recorrido más lógico a seguir por los autores en estas circunstancias. Seyhan afirma que los exiliados de países bajo dictaduras suelen recrear en sus obras los legados culturales destruidos por los dictadores (28). Monserrat Alas-Brun comienza su artículo "The Shattered Mirror: Colonial Discourse and Counterdiscourse about Spanish Guinea" aclarando cómo los autores poscoloniales intentan corregir la imagen distorsionada que se tiene de sus países (163). Y Franz Fanon escribe que se trata de buscar la dignidad que la situación les niega ("National" 154). No obstante, Bill Ashcroft advierte de la dificultad de reproducir la realidad de África y sus naciones. Según él, en un planteamiento muy semejante al que hacía Said en su Orientalism (87-91), la representación de esa realidad está mediatizada por los intereses occidentales. La auténtica realidad africana está superpuesta y mezclada con la idea y la imagen que los intereses occidentales han fraguado para defender sus intereses (11). Aunque Zamora es poco sospechoso de entrar en ese juego, lo cierto es que está construyendo sus memorias desde el exilio y volviendo sus ojos a un pasado en algún caso muy lejano.

La voz poética parece nostálgica con frecuencia. Tanto ella como los personajes que retrata parecen buscar sin éxito en los años pasados una referencia, una identidad que dé sentido a su presente. En "Blues para Armando de Lucas" (42), la voz poética le aconseja "que no te derrote la nostalgia". O el poema "Cine Marfil, Cine Mar" que termina con estos versos:
antes que el relincho
del hipogrifo, en sesión de noche
ahuyente una memoria no apta para menores
y la nostalgia proyecte
contra las desconchadas pantallas
la tremenda palabra FIN.

Pero Bhabha sostiene que esa nostalgia es parte del proceso de poner sentido a su realidad:

Such art does not merely recall the past as social cause or aesthetic precedent; it renews the past, refiguring it as a contingent "in-between" space, that innovates and interrupts the performance of the present. The "past-present" becomes part of the necessity, not the nostalgia, of living. (Location 7)

Revista Iberoamericana, Vol. LXXX, Núms. 248-249, Julio-Diciembre 2014, 1067-1080 
A pesar de que su mirada se dirige con frecuencia a los años de la colonia española, no hay en sus versos una excesiva carga de invectiva contra los blancos o el colonialismo. En "Retrato de damas coloniales" (Memoria 13) la mirada adolescente de Zamora contempla fascinada (y muy probablemente con un componente de deseo) a las señoras blancas. Y los versos finales "que uno jamás volverá a sorprender / en aquel inaccesible abandono" denotan la seducción con la que la belleza de las mujeres y su modo de vida turbaban al joven Francisco Zamora.

En algunos poemas hay homenajes a personajes históricos guineanos, recuerdos de aciagos sucesos de sufrimiento y muerte: como Patronato (Viyil 64) o "Tribu" (25). "El disparo" (37), es un homenaje a una víctima de la violencia política, aparentemente anónima. En "Oficios de tinieblas" (16) aparece una denuncia contra la esclavitud. Pero también hay una aparente auto-aceptación de la porción "occidental" de Zamora. Como Homi Bhabha describe en un artículo titulado precisamente "Frontlines/Borderposts", en tales circunstancias los seres humanos ya no pertenecen a una u otra nacionalidad, sino que son un producto híbrido. Bhabha escribe sobre la identidad originada en los intersticios entre culturas (269). Y la identidad de Francisco Zamora Loboch ya no es sólo la de un africano: los años de la colonia española y sus contactos con otras culturas han conformado una identidad más compleja y heterogénea.

Revelador resulta en ese sentido el poema "Prisionero de la Gran Vía" (39), en el que la voz poética interpela a una madre ausente (quizá incluso fallecida, porque hay un par de referencias a su edad avanzada) para quejarse de que no puede usar sus distintivos africanos en la sociedad de los blancos. No puede usar su taparrabos, mostrar sus tatuajes o lanzar sus gritos. Por el contrario, se comporta como un español acudiendo a los estadios y los mesones. Es relevante que su identidad africana quede significada en el poema mediante signos sensoriales bastante superficiales y estereotípicos. Zamora parece estar abusando de tales indicadores en un rasgo de ironía: son precisamente los atributos que los europeos usaron para poner de relevancia el "salvajismo" de los africanos (justificando así su pretendida superioridad). Pero Bhabha también escribe sobre cómo la identidad queda marcada como imagen, como símbolo (Location 49).

La parte "occidental" de Zamora son, fundamentalmente, las influencias culturales de sus primeros años. En "Estefanía" (Memoria 49-50) la voz poética se dirige a Don Quijote y le habla de novelas del oeste que consumía en su infancia. Zamora ha reconocido la influencia que "las novelas del oeste baratas" y los tebeos han tenido en su formación cultural y su obra (Diálogos 110). Junto a la cultura hispana (o hispanoafricana) de su juventud aparecen referencias anglosajonas (la música afroamericana en "Dies Irae" (35)). Las geografías de sus poemas no son siempre lugares físicos que sus actores recorren, sino que en muchos casos son lugares (comunes o no tanto) culturales, páginas de libros, canciones inolvidables, combates de boxeo.

Sólo en unos pocos poemas hay una clara denuncia de la dominación europea y de su apropiación de la palabra, del texto de la historia. Se trata de "Tinta, pluma y papel"

Revista Iberoamericana, Vol. LXXX, Núms. 248-249, Julio-Diciembre 2014, 1067-1080 ISSN 0034-9631 (Impreso)

ISSN 2154-4794 (Electrónico) 
(22-3), que es una doble referencia a la escritura de los europeos y a los dictados por escrito del poder desde Castilla que aplasta a los indígenas guineanos, y "Andja Bichi” (68), sobre una victoria nativa que es prontamente borrada de los anales españoles, condenada al olvido. Únicamente en esos poemas establece una clara oposición nosotros/ ellos en el que deslinda su vertiente africana del componente europeo. En los demás poemas en los que denuncia abusos y violencia política en su país se trata de atropellos cometidos por cualquiera de las dos dictaduras o, simplemente, no queda claro quién está ejerciendo la violencia. Como en el poema "El disparo" (37), en el que la víctima es abatida "culpable de oler a terruño del amo", pero donde no hay más referencias temporales o políticas (pudiera incluso tratarse de un crimen cometido en cualquier otro lugar del mundo; o en todos los lugares).

La de Zamora es también una poesía de referencias porque cada poema es tan sólo la visión parcial de una historia que queda sin contar, unos acontecimientos que el lector pude saber o intuir, pero no conocer mediante el poema. En el poema "Mama Lapoti" la voz poética trata de una figura femenina que remitifica como un ser mitológico. Pero el lector español desconoce si es una mujer real, una figura de la historia o un ser mitológico. Ese es un recurso que también Zamora maneja perfectamente: inserta referencias culturales y sociales que el lector probablemente posee y que aparecen junto a otras que tal vez le sean desconocidas (tanto por su naturaleza de política local guineana como por tratarse de asuntos personales reales o imaginados por Zamora). El resultado para el lector es un mapa todavía misterioso en esa identidad Zamorana que los poemas indagan o definen.

El trabajo del lector es vital cuando entran en juego esas menciones. Wolfgang Iser utiliza el concepto de "bagaje"; se refiere al bagaje cultural con el que el lector se enfrenta al texto (69). En el caso de la poesía "de referencias" de Zamora es fundamental la función de ese bagaje en el ejercicio de la lectura. Obviamente, diferentes lectores estarán en posesión de bagajes individuales, pero un lector de Guinea conocerá muchas de esas notas culturales e históricas mejor que un lector español (sobre todo teniendo en cuenta el silencio que oficialmente ha rodeado a los asuntos de Guinea Ecuatorial en España). Los lectores españoles pueden sin duda compartir muchas de las referencias europeas o anglosajonas, pero estarán en territorio desconocido cuando se adentren en las citas de historia, cultura o geografía guineanas. Tzvetan Todorov en su "Reading as construction" escribe sobre las "restricciones culturales" que dificultan que un lector ajeno a las realidades culturales del tiempo o el lugar pueda interpretar correctamente el texto (76).

En el caso del lector español de Zamora, su distancia cultural con el autor añade un elemento más al proceso de "re-creación" del texto. No es único, desde luego, y se pone en juego cada vez que un lector abre un libro sobre una cultura que no es la suya. Pero en este particular supuesto, es más complicado incluso porque Zamora es

Revista Iberoamericana, Vol. LXXX, Núms. 248-249, Julio-Diciembre 2014, 1067-1080 ISSN 0034-9631 (Impreso) 
un producto híbrido de la cultura hispana y guineana con algunas otras influencias que se combinan con estas dos.

¿Cuál es el lector implícito de la poesía de Zamora? Habría que comenzar con el proceso de creación, dado que Zamora escribe y publica en España, y él es seguramente consciente de que su lector típico será español (occidental al menos) $;{ }^{1}$ de ahí que la lógica de la obra considera de entrada que el lector tiene que hacer ese esfuerzo interpretativo con respecto a las alusiones culturales que le son desconocidas. La mescolanza de referencias familiares para el lector junto a aquellas que le son ajenas pero que puede conjeturar o saborear exigen del que interpreta un trabajo más arduo, pero también más rico en resonancias poéticas. Walker Gibson en su "Authors, Speakers, Readers, and Mock Readers" proporciona ejemplos sobre cómo ese lector fingido negocia con el texto, cómo se adapta a él y a su tono sin suspender completamente su propio juicio. Y precisamente contempla la posibilidad de que el lector encuentre información y referencias que se toman por supuestas en el texto pero que él no posee. Una solución puede ser interrumpir la lectura considerando que el texto no está dirigido a él como lector, pero la respuesta que Gibson considera más plausible es la de reconocer que no se posee esa información pero asumir en el estatus de "lector fingido" que sí se tiene, porque el texto crea la evidencia de que esa información es importante y apropiada (267).

Así es como el lector español responderá a las referencias que no le son propias ni conocidas. El lector fingido debe estar dispuesto a compartir esa intimidad, a negociar hasta dónde sus identidades son comunes y dónde comienzan a ser diferentes. No tiene necesariamente que sentir empatía con los argumentos anticoloniales de Zamora, sino sólo asomarse al confuso camino que el poeta traza desde su infancia colonial a su exilio.

En una entrevista concedida a la publicación periódica 20 minutos, Zamora afirma que "solo me sonrojo cuando escribo poesía". Es plenamente consciente de cómo expone a los ojos del lector momentos y circunstancias absolutamente íntimas, y cómo establece así un vínculo muy íntimo con el lector. Booth escribe también sobre el arduo trabajo que el lector desempeña mientras lee, y cómo la falta de referencias comunes o la dificultad del texto pueden excluir a algunos lectores (302). Pero, para él, esa labor de descifrar alusiones y sutilezas no es la más importante de las formas de colaboración activa que el lector tiene encomendadas (303). La lectura de una obra literaria depende de que entre el lector y la obra surja una compleja trama de "secret communion, collusion and collaboration" (304). El lector tiene que ser cómplice y colaborador con el texto, y esa es precisamente la acción que la poesía de Zamora excita en el lector.

1 Hago referencia al lector español porque, aunque desconozco la difusión real de la obra de Zamora en Hispanoamérica o entre los lectores hispanos en Estados Unidos, no creo que sea muy amplia fuera de los ámbitos académicos. Cuando uso como intercambiables los adjetivos español, occidental y europeo estoy haciendo referencia al aspecto occidental/colonialista de la identidad española.

Revista Iberoamericana, Vol. LXXX, Núms. 248-249, Julio-Diciembre 2014, 1067-1080 ISSN 0034-9631 (Impreso)

ISSN 2154-4794 (Electrónico) 
Tomando un poema como ejemplo concreto de la creación de ese lector implícito, es particularmente ilustrativo el poema "Elmina Castle" (40-41). De entrada, el lector se enfrenta al título: si ignora (no está en su "bagaje" cultural) que el castillo de Elmina es una fortaleza en lo que actualmente es Ghana, que sirvió primero como centro de comercio de ganado y posteriormente fue uno de las focos más importantes en las rutas del comercio de esclavos, va a empezar su lectura en desventaja. Ante ese inconveniente, el lector real puede interrumpir la lectura por sentir frustración, pero el lector "fingido" que ha caminado ya por las páginas anteriores de la obra (o por las siguientes, no siempre la poesía se lee en el orden numérico de sus páginas) y que ya habrá establecido un vínculo con la cultura y el pasado de Francisco Zamora, probablemente continúe adelante como si tuviera conocimiento del lugar, en realidad esperando descubrirlo en los versos que siguen. El que en el título rece "castle" (en inglés) habrá "excluido" a un número de lectores, que habrán tenido que mantener incluso más firme su máscara de lector "fingido" para seguir adelante.

"A Elmina iremos, vamos / al tercer día de feria", son los dos primeros versos. ¿Quiénes somos “nosotros"? No el lector (ni real ni "fingido"); tampoco el Zamora presente ni el pasado (no es una experiencia personal). El "nosotros" habla de que es una experiencia cultural africana, tanto como el vocabulario, palabras puramente africanas y otras hispanas pero que evocan el exotismo casi estereotípico del continente (ewe y fanti, junto a marfil o monos), Una vez que el lector implícito occidental ha superado la triple exclusión (conocimiento previo del lugar, vocabulario y, sobre todo, ese "nosotros" que lo deja a él fuera), es libre de asomarse a la escena con los ojos de un nativo para contemplar cómo el lamentable comercio con carne humana se ha transformado en una feria, en motivo de fiesta. Sólo para comprobar al final cómo todo aquello está organizado y presidido por el hombre blanco, que ha deshumanizado al negro para vender y comprar a sus semejantes para provecho del extranjero.

La prosa de Zamora está contenida en el ensayo Cómo ser negro y no morir en Aravaca y la novela Conspiración en el Green (el informe Abayak). A pesar de pertenecer a dos géneros distintos, son temáticamente muy semejantes, al igual que ocurría con las dos colecciones de poesía. Cómo ser negro... es una obra maestra del ensayo irónico, una divertida y al mismo tiempo amarga exposición que viene a demostrar al español que pensaba que su país no es racista que estaba equivocado. Pero la avalancha de datos y razones que el ensayo derrama sobre el lector no están organizados en la forma fría, convincente y argumentada que tradicionalmente corresponde al género ensayístico, sino que los argumentos están presentados desde el sentido del humor. Como ejemplo, los títulos de algunos capítulos son "Por qué el blanco es tan listo y el negro tan lerdo", "Pene blanco - pene negro" o el subcapítulo "Fórmulas para trabajar como blanco siendo negro", para terminar con un impagable "Diccionario racista". Zamora utiliza la ironía constantemente para ir desgranando episodios de la historia de España que demuestran el

Revista Iberoamericana, Vol. LXXX, Núms. 248-249, Julio-Diciembre 2014, 1067-1080 ISSN 0034-9631 (Impreso)

ISSN 2154-4794 (Electrónico) 
racismo hispánico, como cuando glosando el episodio del destierro de Boabdil anuncia que le fue aplicada la "Ley de extranjería", la normativa española para la inmigración ilegal y que "embarcáronle en una patera" (11): el pasado excluyente se mezcla en la maestría mordaz de Zamora con el presente racista. Zamora maneja a su antojo todos los estereotipos, tanto los que juegan a favor de las personas de color como en su contra. Desde el tamaño del pene de los negros hasta acontecimientos deportivos, pasando por la visión del africano en la literatura clásica española, todo sirve a Zamora para divertir al lector y demostrar algo a lo que muchos españoles cierran los ojos.

Conspiración en el Green viene a insistir en parecidos temas: la dominación colonial y las diferentes técnicas de manipulación que Europa y Estados Unidos han utilizado y siguen utilizando para controlar a África y sus riquezas. Pero en este caso el formato de la obra es una novela. Dos acciones paralelas ocupan las dos mitades de cada capítulo: un detective annobonés exiliado en España recibe el encargo de los servicios secretos españoles de averiguar qué hay de cierto en los indicios de que se va a producir un golpe de estado contra el dictador guineano Teodoro Obiang y recorre todos los círculos que, en su opinión, pudieran estar involucrados en el proyecto o tener información útil. Al mismo tiempo (y ocupando siempre la segunda mitad de los capítulos), en Sudáfrica un ciudadano libanés intenta convencer a un inglés de la viabilidad y rentabilidad de la idea para que se una al empeño. La trama de la novela en realidad es sólo un pretexto para que los personajes hablen y se transmitan información sobre el pasado y el presente de África y el complejo entramado de corrupción y ambiciones urdido alrededor del continente y sus riquezas naturales. En la entrevista 20 Minutos Zamora sostiene que la información que aparece en la novela es fruto de una rigurosa investigación, pero que la obra "tiene un tono de ficción, porque si fuera un ensayo no se lo leería nadie". Es decir, que en este caso estemos ante una novela y no otro ensayo es sólo fruto de la voluntad de Zamora de alcanzar a un mayor número de lectores. Pero también deja clara en la entrevista su voluntad de acusación:

Tenía mucho material sobre Guinea, y en 2004 me decidí a sacarlo a la luz y analizar el porqué de los golpes de Estado. África está y ha estado gobernada por psicópatas: Amín, Bokall, Bongo, Obiang... Los golpes son una invención occidental, la forma más eficaz y limpia de solventar una situación comercial, Europa quiere tener en sus ex colonias gente que le facilite el negocio.

En ambas obras los temas están relacionados con su poesía en cuanto que África y Guinea son fundamentales. Pero aquí no hay búsqueda más o menos angustiosa de una identidad fragmentada por las circunstancias históricas ni una llamada cómplice al lector, sino una voluntad firme de denuncia, de transmisión de una información que su lector español probablemente no tiene o ignora. Es una prosa militante. Franz Fanon escribía que el individuo colonizado que ha tenido contacto con la cultura y el lenguaje de la

Revista Iberoamericana, Vol. LXXX, Núms. 248-249, Julio-Diciembre 2014, 1067-1080 ISSN 0034-9631 (Impreso)

ISSN 2154-4794 (Electrónico) 
metrópoli (Fanon, quizá irónicamente, utiliza el término mother country) es plenamente consciente de que esa circunstancia lo dota de un poder que muchos otros de sus paisanos no tienen (Black Skins 18-21). Zamora es conocedor del poder del lenguaje, pero él lo utiliza como arma política en su prosa para denunciar. Homi Bhabha es más optimista con respecto a las posibilidades del lenguaje en manos de aquellos que sufrieron la colonia: "In that uncertainty lurks the white-masked black man; and from such ambivalente identificación -black skin, white masks- it is possible, I believe, to redeem the pathos of cultural confusion into a strategy of political subversion" (Location 62).

Francisco Zamora utiliza toda la libertad que el género le concede para explotar numerosos recursos que domina perfectamente: la expresividad del lenguaje coloquial o la ironía devastadora. Por ejemplo, las conversaciones entre el inglés y el libanés tienen lugar en un español castizo lleno de giros coloquiales que proporciona a la conversación un talante de irrealidad y fingimiento. Pero los repugnantes temas, y sobre todo la terrible naturalidad con la que los interlocutores los abordan, encajan perfectamente con ese afectado estilo. En ese sentido, es muy semejante a Cómo ser negro...: se recurre a una técnica para "endulzar" la lectura al lector español y que la información que se desea transmitir lo alcance con más fuerza.

Si Zamora violentó las convenciones del género ensayístico en su irónica primera obra, la novela es un género mucho más flexible que le proporciona un terreno más amplio. Algunas de las obsesiones de su poesía están también presentes en Conspiración en el Green. Es también una obra de geografías y de espacios: cada paso del detective (aunque en la mayoría de los casos se trata sólo de conversaciones con otros personajes en busca de información) guarda una relación estrecha con sus andanzas. Cada lugar está perfectamente ambientado y es el marco espacial impecable para cuanto ocurre. El ajetreo de Madrid, sus calles y bares es el día a día de la investigación de Ton D’Awa; la placidez en Estados Unidos (en contraste con el estridente estereotipo de tiros y persecuciones que los "abnegados ayudantes" del detective conciben desde España) es desasosegante para el profesor guineano que D'Awa va a visitar; la bodega en Villamuriel de Cerrato ("del" en la obra), provincia de Palencia, donde el Club Puta Parió celebra una de sus reuniones en una caja de resonancia intelectual-irónica que dispara los más ingeniosos y disparatados argumentos. La espantosa prisión de Blaybich es casi siempre el espacio geográfico que simboliza Guinea.

Y también las referencias culturales de la hibridez que aparecen en su poesía surgen en las páginas de la novela: hay comentarios sobre música africana (muy probablemente desconocida por el lector español) o citas que incluyen entrañables personajes como Mortadelo y Filemón. Pero todo esto simplemente porque la novela es un género elástico que permite a Zamora divagar en otros motivos que no son exactamente el tema central de la obra. Hay un esfuerzo que sí se pide al lector y que tiene que ver con el tema central de la obra: hay personajes cuya identidad queda incierta en la novela, como

Revista Iberoamericana, Vol. LXXX, Núms. 248-249, Julio-Diciembre 2014, 1067-1080 ISSN 0034-9631 (Impreso) 
el líder guineano que aparece al principio de la obra o el "noble inglés" y el libanés que consideran los pormenores del posible golpe de estado. En el caso del inglés, por la coincidencia del nombre propio y por las muchas referencias que hace a "mamá", parece tratarse de Mark Thatcher, el hijo de la ex primera ministra inglesa que estuvo presuntamente implicado en actividades contra Obiang. Aunque no quiero desvelar demasiados datos para no estropear la lectura de la novela, el destino del golpe también es una incógnita que el lector debe resolver (y que demuestra que lo más importante es la difusión de información y no la trama en sí).

Porque, ¿cuál es el lector implícito que la prosa de Zamora demanda? Cómo ser negro... tiene un claro narratario, ya que el primer capítulo de la obra se titula: "Prólogo para un gachupín o chapetón que pensaba que su país no era racista". En un genial rasgo de mordacidad, Zamora comienza con esta dedicatoria que contiene múltiples niveles: utiliza el término "gachupín", con el que se conoce a los españoles despectivamente en México. Es decir, no sólo obliga al español a mirarse con los ojos desfavorables de un extranjero (que, a su vez, fue un sujeto colonizado por España), sino que lo sacude con la nueva de que, a pesar de que muchos españoles afirmen lo contrario, España sí es un país racista. Pero recordemos que, además del lector real y del lector implícito (o fingido), todo texto literario conlleva otra figura: el narratorio. Tzvetan Todorov, afirma que es "the image of the reader as it is represented in certain texts" (67). Es decir, se trata de un lector explícito, de una construcción más del texto, como un personaje más.

En otra agudeza más, Zamora comienza dedicando el capítulo (y, por extensión, todo el texto) al "gachupín". Pero, ya desde la primera frase del texto, no se dirige a "él", sino que se refugia en una tercera persona de voz ensayística que proporciona información (con agudeza y sátira en su caso, pero siempre en tercera persona). Inicia así un sutil juego de lo que parece "te hablo a ti, pero no vas a escucharme". Crea un narratorio in absentia. Es natural que Francisco Zamora asuma que los destinatarios reales de sus textos van a ser lectores españoles, pero me parece improbable que crea que su lector-tipo va a ser un español de tendencias racistas que ignora (o elige ignorar) tales tendencias en él mismo y la sociedad española.

¿Qué demanda el ensayo de Zamora de sus lectores? Para empezar, por definición de género en el ensayo no es necesario construir misteriosas menciones ni completar huecos en la narración; toda la información debe estar presente en el texto (otra cosa es que Zamora se haya divertido con ella hasta convertirla en un juego de ingenio y parodia). El lector implícito tiene que entrar en el doble juego de información e ironía que Zamora propone. Si la información hiere su sensibilidad como español (o europeo), la burla mantiene al lector "fingido" en el texto. El humor, que en muchos pasajes contribuye a que la información sea comunicada con más eficacia, es también el guía que toma al lector "fingido" de la mano y lo conduce a través de los capítulos. El texto "exige" del lector "fingido" que se adapte al tono de humor del texto para tratar

Revista Iberoamericana, Vol. LXXX, Núms. 248-249, Julio-Diciembre 2014, 1067-1080 ISSN 0034-9631 (Impreso)

ISSN 2154-4794 (Electrónico) 
de cosas muy serias (como si se tratara del Club Puta Parió que aparece en la novela). Y como ese lector no es ya (quizá lo fuera al principio) el gachupín que no pensaba que su país era racista, el texto ha establecido su complicidad frente al otro grupo, ha creado una división retórica en la que el narratorio ha quedado excluido en beneficio del lector implícito, que es al que el texto habla realmente. El texto genera un artificio tan original como eficaz.

En Conspiración en el Green, el lector tiene que cumplir con un trabajo extra, como en la poesía: añadir información por su cuenta o, como Gibson sostenía cuando escribía sobre el lector "fingido", actuar como si poseyera esa información y continuar con el juego que le propone el texto. Pero esa tarea es añadida, porque la demanda de la novela para con el lector implícito es más semejante a la de Cómo ser negro...: dado que la mayor parte de las páginas de la novela contiene información sobre los sucesos políticos que han tenido lugar en Guinea Ecuatorial (o van a tener lugar en el futuro de la novela) tiene que enfrentarse al texto con una gran dosis de curiosidad por la realidad africana. El lector "fingido" encuentra su alter ego en el personaje del detective (aunque éste conoce mucho más que el lector implícito, sobre todo de primera mano) o el inglés que pide incesantemente detalles al libanés. Dado que el argumento detectivesco es tenue y la conversación de los conspiradores ocupa la otra mitad de la obra, el principal interés para el lector "fingido" es saber más de las brutales verdades de la política africana (y europea, claro está).

En ambas obras, el motor del lector implícito es la curiosidad. Pero esa curiosidad podría verse entibiada por la aridez y la cantidad de la información o porque son verdades que el lector europeo puede preferir ignorar. Esa particular "puesta al día" está "atemperada" por variados recursos: el humor, la intriga policíaca, los ornamentos verbales. Si lo que Francisco Zamora pretende fundamentalmente es convencer e informar, ¿está el lector implícito ya convencido de antemano o tiene el autor implícito (el contrapunto del lector implícito) que recurrir a estos recursos para apelar a su benevolencia?

Aunque Booth escribe sobre la necesidad de que el lector implícito someta sus creencias y su ideología al texto para poder disfrutarlo completamente(138), la intención didáctico-política de Zamora en ambas obras es tan evidente que un lector con firmes convicciones contrariamente encontraría muy difícil esa entrega total: no parece posible que quisiera ponerse la máscara del lector "fingido" en este caso. El lector implícito debe estar al menos ya parcialmente convencido. Pero Zamora sabe perfectamente jugar sus bazas: pocos lectores (fingidos o no) van a ponerse del lado del racismo mientras interactúan con Cómo ser negro... Y Conspiración en el green se escuda en la ficción. Aunque muchos occidentales se niegan a admitir la influencia y el control que se mantiene sobre la política africana desde los centros de poder europeos, Zamora obra con perfecta competencia retórica: una vez que el lector fingido porte su máscara y se

Revista Iberoamericana, Vol. LXXX, Núms. 248-249, Julio-Diciembre 2014, 1067-1080 ISSN 0034-9631 (Impreso) 
haya entregado a la obra, es muy difícil escapar al torrente de información y datos que los personajes intercambian.

La obra de Zamora está escindida en una poesía nostálgica y una prosa guerrera. Adopta muy diferentes temas y busca muy diferentes lectores implícitos. No es extraño, porque Zamora es el sujeto híbrido y escindido creado por la situación colonial. Bhahba escribe sobre el desdoblamiento de los individuos producto de la colonización (Location 49-57), y Zamora encaja en esa problemática. Como producto de esa extraña situación de exilio poscolonial, Zamora es un autor escindido entre la melancólica indagación en busca de su identidad compleja y la toma de postura política en contra de una política que mantuvo y mantiene a los pueblos africanos bajo el control de los países europeos. Y también lo exige de su lector fingido: uno tiene que ser cómplice de su indagación y el otro es el destinatario de su denuncia, posiblemente esperando que el lector actúe o reaccione de alguna forma.

Pero que ese desdoblamiento no nos engañe: Zamora sostiene en la entrevista con 20 minutos que "es hora de que el hombre negro escriba su historia". Y eso es exactamente lo que Zamora hace por uno y otro camino. Tanto desde la añoranza y la melancolía como desde la ofensiva verbal, libera esa necesidad de los autores en sus circunstancias de escribir sobre su tierra. Quiere dar voz a su cultura y mostrarla ante el lector europeo, lleve la máscara que lleve.

\section{OBRAS CITADAS}

Alas-Brun, Monserrat. "The Shattered Mirror: Colonial Discourse and Counterdiscourse about Spanish Guinea." Arizona Journal of Hispanic Cultural Studies 8 (2004): 163-76.

Ashcroft, Bill. "Globalism, Post-colonialism and African Studies." Post-colonialism: Culture and Identity in Africa. Pal Ahluwali y Paul Nursery-Bray, eds. Commack, NY: Nova, 1997.

Bhabha, Homi K. "Frontlines/Boderposts." Displacements. Cultural Identities in Question. A. Bammer, ed. Bloomington: Indiana UP, 1994. 269-72.

The Location of Culture. London: Routledge, 1994.

Booth, Wayne. The Rhetoric of Fiction. Chicago: U of Chicago P, 1961.

Fanon, Frantz. Black Skins, White Masks. New York: Grove, 1967.

"National Culture." The Post-Colonial Studies Reader. Bill Ashccroft y otros, eds. London: Routledge, 2002. 153-57.

Gibson, Walker. “Authors, Speakers, Readers, and Mock Readers.” College English 11/5 (1950): 265-69.

Gurr, Andrew. Literary Exile in the Twentieth Century. Martin Tucker, ed. New York: Greenwood, 1991.

Revista Iberoamericana, Vol. LXXX, Núms. 248-249, Julio-Diciembre 2014, 1067-1080 ISSN 0034-9631 (Impreso)

ISSN 2154-4794 (Electrónico) 
Iser, Wolfgang. The Act of Reading. Baltimore: John Hopkins, 1978.

Ndongo-Bidyogo, Donato y Mbare Nogm, ed. Literatura de Guinea Ecuatorial (Antología). Madrid: Sial, 2000.

Ngom, Mbare. Diálogos con Guinea. Madrid: Labrys, 1996.

"La literatura africana de expresión castellana: La creación literaria en Guinea Ecuatorial”. Hispania (1993): 410-18.

Said, Edward. "Orientalism." The Post-Colonial Studies Reader. Bill Ashcroft y otros, eds. London: Routledge, 2002. 87-91.

Serrano, Arancha. "Francisco Zamora Loboch: 'Es hora de que el hombre negro escriba su historia"”. 20 Minutos (Madrid) 10 Nov. 2009. <www.20minutos.es/ noticia/562356/0/paco/zamora/negro>. 28 mayo 2014.

Seyhan, Azade. Writting Outside the Nation. Princeton: Princeton UP, 2001.

Todorov, Tzvetan. "Reading as Construcción”. The Reader in the Text. Susan R. Suleiman y Inge Crosman, eds. Princeton: Princeton UP, 1980.

Zamora, Francisco. Cómo ser negroynomorir en Aravaca. Barcelona: Ediciones B, 1994. Conspiración en el green (El informe Abayak). Madrid: Sial, 2009. Desde el Viyil y otras crónicas. Madrid: Sial, 2008. Memoria de laberintos. Madrid: Sial, 1999. 